\title{
Quality-adjusted labour input: estimates for 1997 to 2007
}

\section{SUMMARY}

ONS headline productivity series, Gross Value Added per unit of labour, are based on the concept of 'labour productivity', with labour input measured in terms of hours, jobs or workers. The drawback of this approach is the implicit assumption that each unit of labour is homogenous - one worker is the same as another, or an hour worked in one sector the same as in any other. However, workers are clearly not the same; they each have an array of different skills and characteristics. Therefore it is possible to produce a more complete measure of labour input based on the quality of the workforce as well as the volume of its input. Qualityadjusted labour input (QALI) does this by differentiating between hours worked according to workers' qualifications, experience, gender and industry. QALI is also used alongside the volume index of capital services in the production of multi-factor productivity estimates. This article updates QALI estimates for 1997 to 2006 and extends the series to 2007 . Results have been produced for the whole economy, the market sector and for six broad sectors.

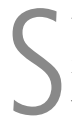
tandard labour productivity measures express growth in output with respect to labour input, implicitly assuming that all labour input is homogenous. However, labour is very much heterogeneous, and the quality, or value, of labour input is affected by numerous characteristics. Most of these differences can be captured in the qualifications, experience, industry and gender of the worker, for reasons explained later in the article. Therefore, the quality-adjusted labour input (QALI) measure uses data on these characteristics to adjust the volume of hours, using relative income shares, to create a more complete measure of labour input and provide an indication on the level of human capital within the economy, compared with a standard aggregation of hours, which takes no account of the composition of labour or workers' relative productivity.

As a result an hour worked by a highly experienced surgeon and an hour worked by a newly hired teenager at a fast food restaurant are treated as equal amounts of labour

$\operatorname{OECD}(2001 \mathrm{a})$

Therefore, it is implicitly assumed that there are two components to labour input: quantity (hours) and quality (labour composition). QALI is based on Labour Force Survey (LFS) microdata, but to ensure consistency with National Accounts and other productivity statistics, the LFS microdata are scaled to compensation of employees, productivity hours and productivity jobs. This article contains the annual update of previous data reported in Dey-Chowdhury and Goodridge (2007), extending the QALI measure to 2007. Since the last publication, all LFS data have been regrossed using the latest population data. Additionally there have been methodological improvements to the compensation of employees series as part of the National Accounts modernisation programme.

QALI is also used alongside its capital counterpart, the volume index of capital services (VICS), which is based on a complementary methodology, as an input to Office for National Statistics (ONS) multifactor productivity (MFP) calculations, where growth in output is attributed to growth in the factor inputs and the Solow residual which largely represents technical change.

\section{Methodology}

To perform the quality adjustment, hours worked are differentiated into $\mathrm{n}$ types of worker $\left(h_{1}\right.$ to $\left.h_{n}\right)$, determined by their characteristics: age (six groups), educational attainment (eight groups), industry (six groups) and gender, resulting in 576 worker types. The hours worked by these different worker types contribute to total labour input $L$ through a function $g$ :

$L=g\left(h_{1}, h_{2}, \ldots ., h_{n}\right)$

Following the OECD (2001) recommended 
methodology, the growth in qualityadjusted hours can be represented as a Törnqvist index:

$\frac{\Delta L(t)}{L(t)}=\sum_{i}\left[\frac{w_{i}(t)+w_{i}(t-1)}{2}\right] \frac{\Delta h_{i}(t)}{h_{i}(t)}$

Economic theory states that in competitive markets with constant returns to scale, labour will be hired until its marginal cost (wage) equals its marginal revenue product, or its marginal productivity. Therefore, by using income shares as a weight, the relative productivity of workers is taken into account when measuring their labour input. The assumption that workers are paid their marginal product will hold true even if firms do not behave competitively in the labour market, and is only violated if firms are monopsonists, where the firm has a degree of monopoly power in the purchase of labour.

So, in equation (2), $w_{i}(t)$ is the share of total labour income paid to group $i$ in period $t$, the weight used is the average of $w_{i}(t)$ and $w_{i}(t-1)$ and the income shares sum to one. The use of data from the current and previous period to weight the index is a feature of Törnqvist indices, making them more current or representative measures. The Törnqvist index is also a widely used form in economic analysis, particularly in regard to quality-adjusted labour measures ${ }^{1}$ (Bell et al 2005).

\section{Labour characteristics}

As mentioned previously, hours worked are differentiated into 576 categories according to the workers' characteristics. These characteristics are broken down into relatively homogenous groups, chosen to capture quality change without stretching the LFS dataset too far. The groups of labour characteristics are shown in Table $\mathbf{1}$.

\section{Age}

Age is included as a proxy for work experience. Although imperfect, as it takes no account of periods of unemployment or inactivity, the assumption is that older workers tend be more productive due to their greater experience, and therefore receive greater compensation for their labour. Alternatively, it has been suggested

Table 1

\section{Labour input characteristics}

\begin{tabular}{|c|c|c|c|c|}
\hline Gender & Age & Education & Industry & Industry description \\
\hline Male & $16-19$ & Higher degree & $\mathrm{ABCE}$ & Agriculture, hunting, forestry, fishing, mining quarrying, utilities \\
\hline \multirow[t]{8}{*}{ Female } & $20-29$ & NVQ5 (excluding & $\mathrm{D}$ & Manufacturing \\
\hline & $30-39$ & higher degree) & $\mathrm{F}$ & Construction \\
\hline & $40-49$ & NVQ4 & \multirow[t]{2}{*}{ GHI } & Wholesale and retail trade, hotels and restaurants, transport \\
\hline & $50-59$ & NVQ3 & & storage and communications. \\
\hline & \multirow[t]{4}{*}{60 plus } & NVQ2 & $\mathrm{JK}$ & Financial intermediation, real estate, renting and business activities \\
\hline & & NVQ1 & \multirow[t]{3}{*}{ LMNOPQ } & Public administration and defence, education, health and social \\
\hline & & Other qualifications & & work, other social and personal services, and extra-territorial \\
\hline & & No qualifications & & activities \\
\hline
\end{tabular}

that younger workers may be more dynamic and innovative than their older counterparts (Bell et al 2005). However, if this is true in some cases then, provided labour markets are competitive, these workers will be paid their marginal product and growth in hours will be weighted accordingly.

\section{Gender}

Gender is chosen because of the persistent pay differential that exists between males and females, even after holding other factors constant. Although not a driver of quality change itself, it may represent hidden characteristics such as an increased tendency to take career breaks or to fulfil part-time posts that are not as well paid. Therefore, this compliments, or improves, the use of age as a proxy for work experience, as well as helping to explain the pay differential. However, if the pay differential reflects discrimination, then the assumption that workers are paid their marginal product is violated, resulting in hours growth being weighted incorrectly and the quality adjustment carrying a downward bias. This is a weakness of the model.

\section{Education}

This is measured as the highest qualification attained and used as a proxy for skills. Qualifications either act as a signal of ability to employers or they provide the knowledge for specific job requirements. This characteristic is the primary driver of the index. Due to the increasing prevalence of higher degrees and their growing association with higher pay, they are included as a stand-alone category. However, there is a trade-off between the number of categories and the constraints of the sample size and it has been decided that eight qualification levels provides an optimal balance.

\section{Industry}

Although primarily included for the observation of industry trends and the use of QALI in industry-level MFP, this category also helps capture inherent differences in skill and productivity that exist between industries. The industry categories chosen are broad partly because industry is self-reported in the LFS, leading to inaccuracy of response, and also because of small sample sizes for some sectors.

\section{Data source}

The LFS is a continuous household survey that currently covers approximately 53,000 households every quarter and contains data on educational attainment, industry, gender and age for men aged 16 to 64 and women aged 16 to 59 . Due to discontinuity in the educational attainment variable, and the recent conversion of data from seasonal to calendar quarters, QALI can only be produced from 1997 onwards.

\section{Scaling}

To improve consistency with the National Accounts and ONS headline productivity measures, various components of QALI are scaled to ONS aggregates. Specifically:

- gross weekly pay is scaled to National Accounts compensation of employees

- actual hours worked are scaled to productivity hours ${ }^{2}$

- total jobs are scaled to productivity jobs

The first adjustment improves the consistency of the LFS-based data with

\section{Box 1}

\section{Index numbers}

The main feature of the Törnqvist index is that the weight used is an average of the weight in the current and previous period making it a more up-to-date and representative measure. Because of this feature, it tends to be used on historic datasets.
Another difference between the Törnqvist index and more conventional indices such as the Laspeyres, is that the former is calculated geometrically rather than arithmetically, meaning that the Törnqvist index is a weighted, geometric average of its components, making it a more representative measure (Goodridge 2007). 
National Accounts compensation of employees as, ideally, growth in hours would be weighted using total labour compensation. While the LFS only provides information on wages and salaries, compensation of employees also includes bonuses and income in kind. Additionally, as with other household surveys, LFS microdata include proxy responses, missing responses and inaccurate data. In this case, respondents have particular difficulty recalling their pre-tax income or bonuses accurately. Scaling the data helps overcome these issues. Scaling the jobs and hours data to the labour productivity jobs and hours data also helps to partly overcome the inaccuracies in the LFS industrial breakdown.

\section{Data issues}

Approximately 30 per cent of responses in the LFS dataset are proxy responses, meaning that they are responses given on someone else's behalf. In order to check that this does not cause bias in the estimation of QALI, the qualityadjustment of hours was carried out on personal responses only and the relationship between adjusted and unadjusted hours remained the same. It was therefore decided to leave proxy responses in the data, since excluding them would create additional problems, such as a reduced sample size and grossing to population totals.

The inclusion of the self-employed also poses an issue, as wages for the self-employed are not recorded in the LFS, or any other survey. This is because self-employed people remunerate themselves for a combination of labour and entrepreneurial effort, and it is impossible to distinguish between the two - it would be a subjective division if it were done at all. As a result, the wages of the employed with similar characteristics are used as an approximation for the wages of the self-employed.

As mentioned above, the LFS dataset has recently been converted from seasonal to calendar quarters, creating greater consistency with other input and output data. However, calendar quarter data are only available back to 1997 and nonoverlapping seasonal data for 1996 only covers March to November (spring to autumn). To avoid this impacting the index by distorting growth rates, and to maintain a consistent set of data based on calendar quarters, it has been decided to begin the series in 1997 rather than $1996 .^{3}$

Also, to measure labour's true input to production as accurately as possible, no restrictions have been placed on outliers, and actual hours rather than usual hours are used because, conceptually, it is the former that need to be measured.

\section{Results}

The results for the whole economy are shown in Figure 1, where the QALI index can be compared with the unadjusted series, a standard aggregation of hours based on LFS microdata, and represented in index form. The difference between the two is the quality adjustment, often referred to as 'labour composition."

As can be seen in Figure 1, over the period 1997 to 2007, the gap between the QALI and unadjusted hours series has been growing consistently. The trend continued throughout 2007; while growth in hours peaked and began to fall towards the end of the year, growth in QALI merely stagnated, suggesting that the quality of labour has consistently improved throughout the time period and continues to grow into 2007.

As a comparison, the ONS LFS headline series, used in the production of labour productivity series, is also shown in the chart. As can be seen, the series follows a similar trend to the unadjusted hours series, but diverges slightly. This is a result of the unadjusted hours series being presented as a Törnqvist index, to maintain consistency with QALI.
Figure 2 charts labour composition at industry level and shows that, over the series, the quality of labour has fallen in both 'Construction' and a broad industry group that includes 'Agriculture, forestry and fishing, 'Mining and quarrying', and 'Utilities'. However, these industries did show an improvement in 2007

Data for all other industries show that labour composition has increased significantly since 1997, with the strongest growth occurring in 'Finance and business services' and another broad industry group including 'Public sector services', their private sector counterparts and 'Personal and recreational services'. Growth in labour composition in 'Distribution, hotels and restaurants' and 'Transport' also picked up over 2006 to 2007. Therefore, there has been a significant increase in human capital in most industries over the period concerned.

\section{Market sector estimates}

Since 2007, a market sector version of QALI has also been produced. The results are consistent with the whole economy estimates and with the market sector definitions used in Marks (2007) and the Productivity First Release.

Indices for QALI and unadjusted hours in the market sector are shown in Figure 4. Unfortunately, the market sector hours series to which QALI is scaled is only available

\section{Figure 1}

\section{QALI, whole economy}

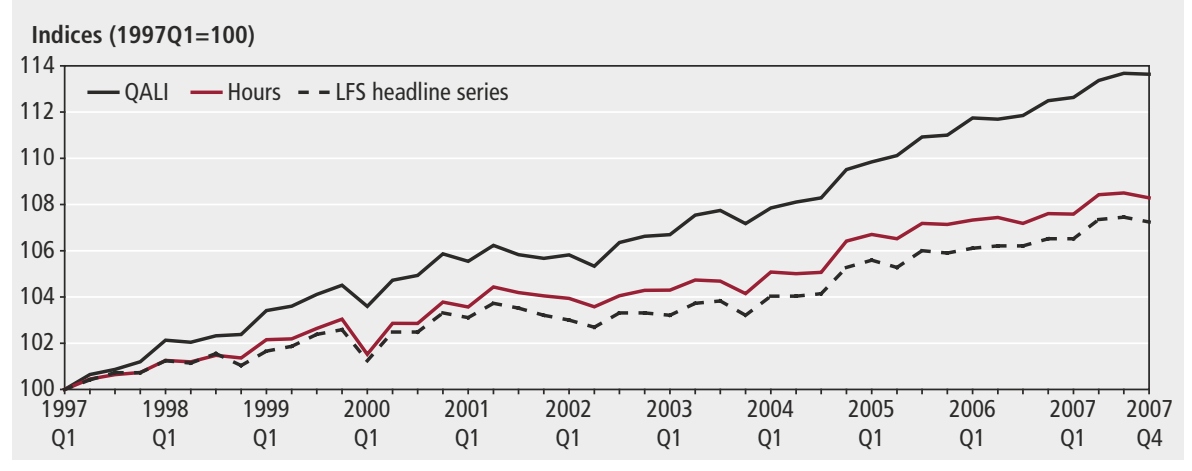

\section{Figure 2}

\section{Labour composition: by industry group}

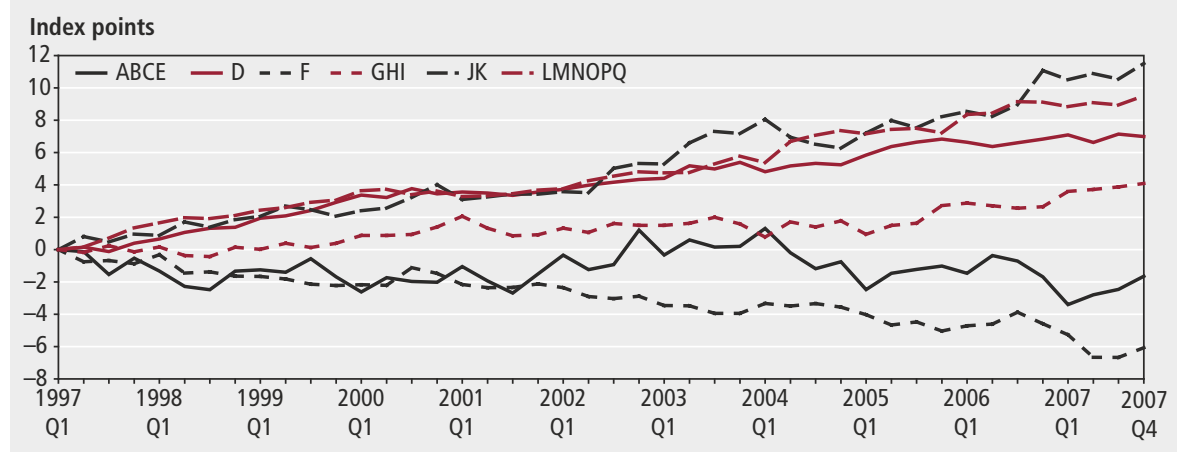




\section{Box 2}

\section{Comparison with alternative measures}

The measurement of the quality of labour input is becoming an increasingly important field in productivity analysis, with both researchers and policy makers interested in skill levels (and therefore gaps) in the labour market, human capital stocks and the actual value of labour input. Therefore, alternative measures of labour quality in the UK have been developed in recent years. Figure 3 charts the ONS measure alongside those produced at the Bank of England and as part of the EUKLEMS project.

As can be seen, the series follow very similar trends, particularly between 1997 and 2002. After 2002, the EUKLEMS series initially show stronger growth in both the quality-adjusted and unadjusted measures, with the ONS series ultimately continuing

to grow to a similar level. Differences in the profiles are due to each being constructed using a slightly different methodology, and in some cases, different sources. In the Bank of England series, the data are split by five age-groups and four education levels, as well as by gender (Bell et al 2005). In the case of EUKLEMS, the LFS data are split by gender, three age-groups and three education levels, and hours for each worker type are derived from industry averages. ${ }^{5}$

In the case of the BoE data, the unadjusted hours series is slightly lower than both the ONS and EUKLEMS series - the main reason behind this is the decision to use 'total actual hours' compared with the use of 'usual hours' by the Bank of England.

\section{Figure 3}

\section{ONS, Bank of England and EUKLEMS comparison}

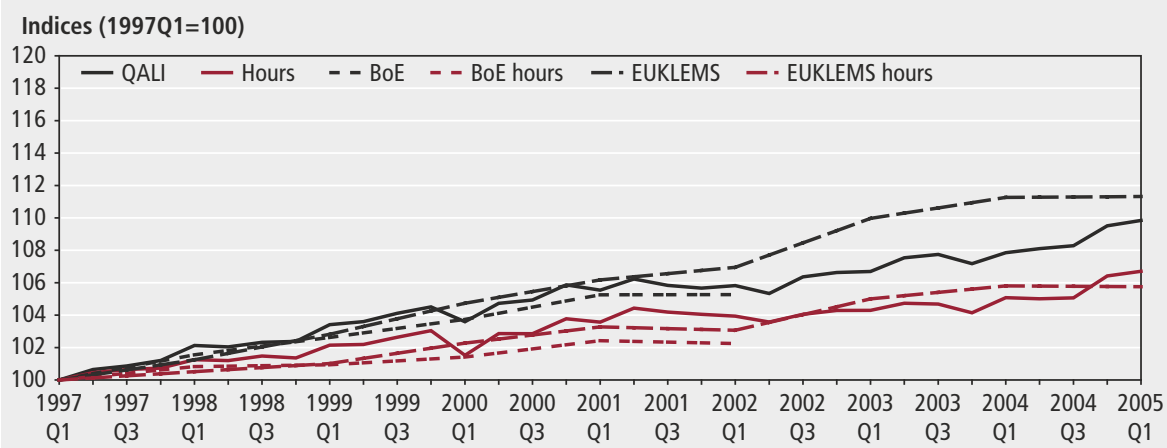

\section{Figure 4}

\section{Market sector QALI}

\section{Indices (1999Q2=100)}

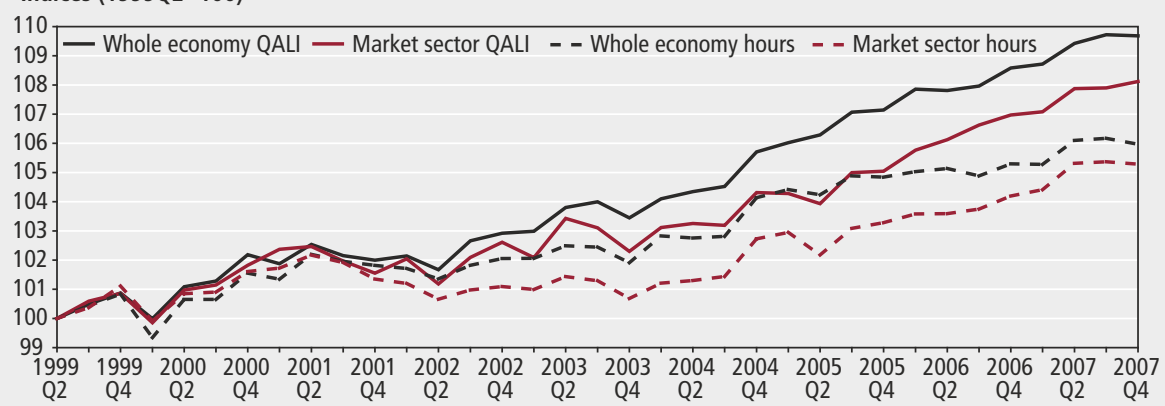

as far back as the second quarter of 1999 . Therefore, the whole economy measure has been rebased to start in the same period, in order to serve as a comparison.

As can be seen, there has been strong growth in quality-adjusted hours in the market sector, with overall growth at a similar level to the whole economy. Indeed, the market sector QALI continued to grow throughout 2007, whereas growth in unadjusted hours was relatively flat.

\section{Revisions}

The data presented in this article contain revisions to the full QALI series for several reasons:
- this is the first time a full set of calendar quarter data have been available, so the reference periods for each data point have changed slightly

- in 2007, the LFS microdata were regrossed to the latest population estimates

- there have been revisions to the hours and jobs data used in the production of ONS productivity measures

- there have been substantial revisions to the compensation of employees series due to a change in methodology as part of the re-engineering of National Accounts
- changing the series endpoints has a slight effect on the seasonal adjustment process

\section{Notes}

1 Previously QALI has also been produced as a Laspeyres index to improve compatibility with its capital counterpart, VICS. However, the introduction of calendar quarters and the use of Q1 (rather than the less seasonal spring quarter) to chain the series has introduced an element of 'time-reversal' in some series, reducing the validity of the results. This means that if, for example, hours worked increase, and subsequently decrease, the index fails to decrease all the way back and instead returns to a higher level. This is a well known property and is one of the reasons why superlative indices, such as the Törnqvist, are preferred. Therefore, the series are now only available as Törnqvist indices.

2 Productivity hours and jobs are definitions used in the calculation of the headline ONS productivity measures. Productivity hours and jobs provide the best measures of labour input for productivity purposes as they are produced using more reliable proportional breakdowns from both short-term and annual business surveys and constraining to LFS aggregates.

3 Conversion to calendar quarters and the introduction of a new occupation variable has resulted in income weights not being created for 2001 Q1. Therefore, gross pay in main and second jobs has been imputed using data from the quarters either side.

4 All results are available on the ONS website at www.statistics.gov.uk/statbase/product. asp?vlnk=14206 
5 Further information on the EUKLEMS project can be found at www.euklems.net

\section{CONTACT}

(《)elmr@ons.gsi.gov.uk

\section{REFERENCES}

Bell V, Burriel-Llombart P and Jones J (2005) 'A quality-adjusted labour input series for the United Kingdom (1975-2002)', Bank of England Working Paper No. 280.

Camus D and Lau E (2006) 'Productivity measures and analysis: ONS strategy and work programme', Economic Trends 632, pp 14-21 and at

www. statistics. gov.uk/cci/article. asp id $=1603$

Dey-Chowdhury S and Goodridge P (2007)

'Quality-adjusted labour input: estimates for
1996 to 2006', Economic \& Labour Market Review 1(12), pp 48-54 and at www.statistics.gov.uk/cci/article. asp?id=1906

Goodridge P (2007) 'Methods Explained: Index Numbers', Economic \& Labour Market Review 1(3), pp 54-7 and at www.statistics.gov.uk/cci/article. $a s p ? i d=1743$

Marks C (2007) 'Market sector GVA productivity measures', Economic \& Labour Market Review 1(3), pp 47-53 and at www.statistics.gov.uk/cci/article. asp $? \mathrm{id}=1742$ Organisation for Economic Co-operation and Development (2001) 'Measuring Productivity - OECD Manual'.

Wallis G and Dey-Chowdhury S (2007) 'Volume of capital services: estimates for 1950 to 2006', Economic \& Labour Market Review 1(12), pp 37-47 and at www.statistics.gov.uk/cci/article. asp? id =1905 